\title{
Psychiatry interdisciplinary: the Berlin Congress of Psychiatry
}

\author{
Frank Schneider • Michael Grözinger
}

Published online: 1 October 2011

(C) Springer-Verlag 2011

The German Association for Psychiatry and Psychotherapy (DGPPN) has agreed once more this year to provide you with a printed taste of the annual DGPPN Congress in November 2010. For this purpose, we have chosen 18 of the major topics presented at Berlin to be part of this supplement of the EAPCN. Thereby, the articles are available for an international audience that is increasingly attracted by the conferences. While the event took place on a national level originally, professionals from our neighboring countries started to join in and spread the word. During the last two years, we supported this trend by offering an International Track with $25 \%$ of the sessions in English language continuously paralleling the German program. Simultaneous translation was provided for the most central events of the conference. We will continue and extend this service for our foreign guests.

Over the years, the conference has developed into one of the most important events of its kind in Europe. In 2010, the Berlin Congress attracted well over 10,000 participants and offered 555 symposia, workshops, and other meetings. More than $20 \%$ of the attendees came from 50 countries other than Germany. Besides presenting a high professional standard, the Berlin Congress is an excellent opportunity to meet colleagues that you might not have seen in years and to exchange ideas in a pleasant and familiar atmosphere. To further support the international participation at the conference in 2010, we invited 250 psychiatric colleagues from eastern European Countries as well as an additional group of psychiatrists from Aserbaidschan to join our

F. Schneider $(\square) \cdot$ M. Grözinger

Klinik für Psychiatrie, Psychotherapie und Psychosomatik

Universitätsklinikum Aachen, Pauwelsstr. 30,

52074 Aachen, Germany

e-mail: fschneider@ukaachen.de conference. We are confident that all these activities will make the Berlin Congress of Psychiatry more attractive and more colorful as well as increase its quality. At the same time, we strive to preserve the familiar atmosphere we have been used to for many years.

In 2010, the conference theme was "Psychiatry interdisciplinary." In a rather broad sense, we intended to address psychiatry in dialog with the other medical disciplines, the other sciences but also with society as a whole. It has taken a long time for psychiatry to arrive in the midst of medicine and science. Presently, we have the impression that psychiatry is approaching the middle of the society. The relevance of mental disorders is constantly growing. Some mental illnesses, for example depression, have gained social acceptance in the meantime. Others such as schizophrenia and substance dependence are still subject to unchallenged stigma. A lot of communication and cooperation will be needed to make our work so efficient that we can cope with these upcoming challenges.

One important aspect that still presents a burden on the relationship between psychiatry and society is the role of German psychiatry during the Nazi regime. This topic dominated the last conference, and four of the articles in this journal deal with it. Seventy years have since passed, but we are just beginning to understand the vicious liaison between our discipline, the psychiatrists and the professional organizations, and the political crimes of that period. Almost two years ago, the DGPPN decided to mandate an independent international commission of historians with an investigation of the professional association's activities during these years. First, results were presented at the Berlin Congress 2010 and are included in this supplement. The annual convention of the DGPPN in Berlin in 2010 was dedicated to the victims of these crimes and to the issue of the association's responsibility. Around 3,000 
psychiatrists gathered at the main commemorative event on November 26, 2010 to honor the memory of victims who were killed and subjected to ethically unjustifiable research and forced sterilization, and of their colleagues who were forced into emigration. The speech held by the President of the DGPPN at the event is given here.

Sport psychiatry was another topic at the conference. Recently, the tragic suicide of the German football goal keeper Robert Enke highlighted the dilemma of top athletes who need help with mental disorders. One article in this issue provides some insight into the taboo concerning the weakness of the seemingly strongest of our society. Exercise and physical activity, another theme related to sport psychiatry, has become a major issue in various fields of medicine that we certainly will be concerned with in the future.

Other articles deal with psychiatry in its relation with society: the efforts to stop the suffering and to start the treatment for psychiatric patients in Bali, the present situation of psychiatry in Italy, the possibilities to measure stigma, and the role of the media in German psychiatry. Beside these topics, there are many more interesting articles. Please take the opportunity to scroll through the Journal that the German Association for Psychiatry and Psychotherapy has prepared for you.

Acknowledgments This supplement was funded by the German Association for Psychiatry and Psychotherapy (DGPPN). 